\title{
Stunting and its Determinant Factors among Early Adolescent School Girls of Gondar town, northwest Ethiopia: A school based cross -sectional study
}

\section{Azmera Tamrat ( $\sim$ azmeratamrat61@gmail.com )}

University of Gondar

\section{Yigizie Yeshaw}

University of Gondar

Abel Fekadu

University of Gondar

Research article

Keywords: Stunting, Early adolescent girls, Gondar, Ethiopia

Posted Date: July 15th, 2019

DOl: https://doi.org/10.21203/rs.2.11379/v1

License: (c) (i) This work is licensed under a Creative Commons Attribution 4.0 International License.

Read Full License 


\section{Abstract}

Introduction: Stunting in adolescent have an effect on physical growth, intellectual capacity, educational achievement, work capacity and more importantly it maintains an intergenerational malnutrition burden. Stunting has been considered as a problem of children's at early age and adolescent girls of tomorrow mothers have been neglected and studies conducted on this area are very scarce. Methods: we conducted a school based cross-sectional study to assess the prevalence and determinant factors of stunting among early adolescent school girls (age 10-14 years) of Gondar town. A multi stage sampling method was used to select a sample of 662 adolescent girls in selected primary schools in Gondar Town. Pretested structured interviewer administered questionnaire was used to collect the required data. We used SPSS Version 20.0 and WHO Anthro-plus software to analyze the data. Bi-variable and multivariable logistic regression analyses were run to identify factors associated with adolescent stunting. Adjusted odds ratio with its $95 \%$ confidence interval and a P-value $\leq 0.05$ was used to declare a statistical significant. Results: We estimated a prevalence of stunting to be $27.5 \%$ [95\% Cl: $25.5 \%-29.5 \%$ ]. The odds of stunting in adolescent girls was found to be higher among those in grade 5 [AOR; $95 \% \mathrm{Cl}: 1.90 ; 1.13$ $3.20]$, had a meal frequency of less than or equal to three times per day [AOR; $95 \% \mathrm{Cl}: 2.37 ; 1.60-3.50$ ], and those who are from food insecure families [AOR; $95 \% \mathrm{Cl}: 2.52 ; 1.70-3.73]$. On the other side, adolescent girls whose their mothers' were government employees [AOR; $95 \% \mathrm{Cl}: 0.48 ; 0.26-0.89$ ] and merchants [AOR; $95 \% \mathrm{Cl}: 0.43 ; 0.28-0.67]$ were less stunted as compared to adolescent girls who had a mother who were housewife's. Conclusion: we found that stunting in early adolescent school girls become a significant public health problem and much needs to be done to improve nutritional status of girls in the first 1000 days of perinatal period to reduce a burden of stunting during adolescent period.

\section{Abstract}

Introduction: Stunting in adolescent has an effect on physical growth and cognitive development of the new-born and its effect also continues to manifest in the next generation. So far stunting has been considered as a problem of children's at an early age and studies on the area of adolescent girls of tomorrow mothers have been neglected in Ethiopia.

Methods: We conducted this school-based cross-sectional study to assess the prevalence and determinants of stunting among the early adolescent school girls of age 10 to 14 years in Gondar town. A multi-stage sampling method was used to include 662 adolescent girls in selected primary schools. A pretested, structured, and interviewer-administered questionnaire was used to collect the required data. SPSS Version 20.0 and WHO Anthro-plus software were used to analyze the data. Bi-variable and multi-variable logistic regression model were fitted to identify determinants of stunting. Adjusted odds ratio with its $95 \%$ confidence interval was calculated and a P-value $\leq 0.05$ was used to declare a statistical significance.

Results: The prevalence of stunting was $27.5 \%$ [95\% Cl: $25.5 \%-29.5 \%]$. The odds of stunting in adolescent girls was found to be higher among grade 5 students [AOR; $95 \% \mathrm{Cl}: 1.90 ; 1.13-3.20$ ], those who reported a daily meal frequency of less than or equal to three [AOR; $95 \% \mathrm{Cl}: 2.37 ; 1.60-3.50]$, and 
those who were from a food insecure families [AOR; $95 \% \mathrm{Cl}: 2.52 ; 1.70$ - 3.73]. On the other side, adolescent girls whose their mothers' were government employees [AOR; $95 \% \mathrm{Cl}: 0.48 ; 0.26-0.89$ ] and merchants [AOR; $95 \% \mathrm{Cl}: 0.43 ; 0.28-0.67$ ] were less stunted as compared to adolescent girls whose their mothers were housewife.

Conclusion: we found that stunting in an early adolescent school girls became a significant public health concern and much more needs to be done to improve their nutritional status in their first 1000 days of perinatal period. A special school based nutritional program might be required to reach this adolescent of tomorrow mothers.

Key words- Stunting, Early adolescent girls, Gondar, Ethiopia

\section{Introduction}

According to the United Nations (UN) definition, early adolescent included individuals in the age category of $10-14$ years and they roughly cover $20 \%$ of the total world population with a higher demographic weight in the low-income countries $(1,2)$. Adolescence is a period of dramatic physical, cognitive, social, and emotional changes by which $15-20 \%$ of adult's height gained. This faster growth period of adolescence requires adequate nutrition to maintain their physical, cognitive, and linear growth $(3,4)$.

Stunting is a key indicator of long-term chronic under-nutrition that reflects a failure to reach a linear growth due to prolonged food deprivation and illnesses during an early stage of life (5). The adolescent girls are potential risky groups for stunting as they are traditionally married at an early age and their increased nutritional demand for pregnancy and lactation in later life $(5,6)$. Stunting in the adolescent is a reason for delayed physical growth, poor educational achievement, and intellectual capacity. Similarly, it can result in decreased offspring birth weight, work capacity, poor social skills, behavioral problems, and vulnerability to contracting metabolic diseases during their adulthood (7-9). More importantly, through fetal programming, stunted adolescent girls are more likely to give birth to the underweight baby that will also be highly at risk for stunting and chronic health problems in later life $(6,10)$.

Prevalence studies conducted so far estimated a varying level of stunting in the adolescent school girls. The prevalence of stunting in the adolescent girls was $48 \%$ in Bangladesh and $47 \%$ in Nepal $(11,12)$. In two Indian studies, $46.6 \%$ (13) and $34.2 \%$ (11) of the rural adolescent girls (10-19 years) were stunted. In Ethiopia, the prevalence of stunting in the adolescent girls range from $26.5 \%$ to $41.8 \%$ (14-16).

Different factors have been reported to contribute to the high stunting prevalence in early adolescent girls. Adolescents born in large family size, use unimproved sources of drinking water (17), who born from uneducated mothers, and food insecure households (18) are more likely to be stunted. Being exposed to the contaminated environment and poor hygiene (19), meal skipping in the last two weeks, and having a poor dietary diversity score are also associated with an increased risk of stunting (20). Even though the adolescent stunting was a common problem in Ethiopia, limited researches have been published in particular to the early adolescent school girls of age 10-14 years. Therefore, this study has been 
conducted to assess the prevalence of stunting and its determinant factors among the early adolescent school girls in Gondar town.

\section{Methods}

\section{Study design and population}

A school-based cross-sectional study was conducted to estimate the prevalence of stunting and its associated factors among the early adolescent girls of age 10-14 years attending a primary governmental schools in Gondar town in January 2016 G.C. Gondar town is located in Northwest part of Ethiopia far about $735 \mathrm{~km}$ away from Addis Ababa, the capital city of Ethiopia. Forty-three public primary schools are found in Gondar town. There are 16,331 students attending in those governmental schools and of these, 8,885 were early adolescent girls. These number could represent more than $95 \%$ of the early adolescent girls in the community with almost similar socio-demographic characteristics. All early adolescent girls present in selected governmental primary schools at the time of data collection were included.

\section{Sample size and sampling procedure}

The sample size was calculated using a single population proportion formula by considering the following assumptions: stunting among adolescent girls in Amhara region $(P=0.315)(17), 5 \%$ margin of error, $95 \%$ confidence level, non-response rate of $10 \%$, and a design effect of 2 . Accordingly, the final sample size estimated was 731 . In the first stage, 10 primary schools were selected from 43 primary schools using a lottery method ( $23 \%$ of all primary schools). In the second stage, the total number of adolescent girls to be included were proportionally allocated to the size of primary schools and the final study subjects were selected from each included primary schools by using a systematic random sampling method.

\section{Data collection procedures and quality}

Data were collected using a pre-tested, structured and interviewer-administered questionnaire. The questionnaire is prepared in English and translated to Amharic and to check for its consistency, the questionnaire was back-translated to English by language experts. Food security was assessed using the 9-item module and the sum of its affirmative responses was taken (22). The weight of adolescent girls was measured to the nearest $0.1 \mathrm{~kg}$ using a calibrated SECA weighing scale with a light closing and without shoes. The height of adolescent girls was measured to the nearest $0.1 \mathrm{~cm}$ on standing position without wearing shoes using the same device that has scale and sliding headpiece. Four diploma nurse data collectors and one BSc nurse supervisor were recruited and trained for data collection. To assure the data quality, the questionnaire was pre-tested. Weighing scale was calibrated to zero before taking every other measurement. The collected data were reviewed and checked for completeness before data entry. 


\section{Variables of the study}

Our dependent variable was stunting in the early adolescent (defined by WHO as a period of life spanning the ages between 10-14 years) and it was measured as height for age Z-score (HAZ) of below minus two standard deviations (-2 SD) from the median value of the WHO reference standard. Our independent variables include: education level of the student, educational status of the family, family income, employment status of the family, family size, information about food types such as teff (a type of crop used to make Enjera, a traditional food in Ethiopia), food security status, frequency of meal per day, source of water, and hand wash habit. These independent variables were collected by interviewing the students as most of the questions were easy to answer by the students. Based on our extensive literature searching, this co-varieties were repeatedly reported in other studies. The way we measured all of these variables could be found in our data collection tool attached to this submission.

\section{Data processing and analysis}

After checking the collected data for completeness, it was entered into Epi-data version 3.1 and exported to SPSS version 20.0 for analysis. The anthropometry measurement of height for age was calculated by WHO Anthro-plus software and those adolescent girls with less than -2SD were considered to have stunting. The food security status of households with a row score of $0-1$ was taken as food secure and a row score of $2 \&$ above was taken as food insecure (22). Bi-variable and the multivariable logistic regression analysis were done to assess the association between different explanatory variables and stunting. All variables with a p-value $<0.2$ in the bi-variable analysis were entered into the multivariable logistic regression model. Odds ratio with its $95 \%$ confidence intervals were estimated to identify predictors of stunting. A P-value $<0.05$ was considered as statistically significant. Model fitness was checked using the Hosmer and Lemeshow goodness of fit test (P-value $=0.99)$.

\section{Ethical consideration}

Ethical clearance of this study was granted by an Ethical Review Board of the University of Gondar. Permission was also obtained from Gondar town Education Office and from selected schools. Written consent from the guardians and a verbal assent from the study participants was secured prior to data collection. The information collected from this study was kept confidential. Those who were severely stunted were counseled about their nutritional condition.

\section{Result}

\section{Socio-demographic characteristics of the respondents}

Six hundred sixty-two study participants were included with a response rate of $90.56 \%$. The mean and standard deviation ( $\pm S D$ ) age of the study participants was $12.85( \pm 1.23)$. Most of, $545(82.3 \%)$, the study participants were Orthodox. Among the respondents, $388(58.6 \%)$ had a family size of five and above. 
Four hundred eighty-one (72.7\%) of the study participants had alive mother and father and $182(27.5 \%)$ of the study participants were in grade seven. (Table 1 )

\section{Nutrition and health-related variables of the respondents}

From the total of 662 early adolescent school girls (participants), 402(60.7\%) reported that they had a meal frequency of three and above per day. More than three fourth of the participants, $499(75.38 \%)$, had a snack. Three hundred twenty-two (48.6\%) of the study participants had a food insecurity problem. Regarding the availability of pure water, $34(5.1 \%)$ of the study participants use river water. One hundred twenty-nine (19\%) of the participants had diarrhea history in the last 2 weeks. Four hundred seventy-one (71.1\%) of the participants were heard information about food types from different sources (media, health professionals, school). (Table 2)

\section{Prevalence and associated factors of stunting}

The overall prevalence of stunting in this study was $27.5 \%$ (95\% Cl: $25.5 \%-29.5 \%)$. From this, $60(9.1 \%)$ of the study participants had severe stunting. On bi-variable logistic regression analysis, stunting was found to be associated with a grade level of students, education level of their partner, the employment status of their partner, parental alive status, the frequency of meal per day, food security status, and with whom they live. However, after adjusting for other covariates, grade level of students, the employment status of their mother, frequency of meal per day, and food security status were significantly associated with stunting.

The odds of stunting among grade five students was 1.9 times higher than grade eight students [ $95 \% \mathrm{Cl}$ : 1.13 - 3.20]. Students whose their mother were government employee had a $57 \%$ reduced chance of being stunted than those whose their mother were housewives [AOR $=0.43 ; 95 \% \mathrm{Cl}: 0.28$ - 0.67]. Students who had a merchant mother had a $52 \%$ reduced chance of being stunted than those whose mothers were housewives [AOR $=0.48,95 \% \mathrm{Cl}: 0.26-0.89]$. The odds of stunting among students who had a meal frequency of $\leq 3$ times per day was 2.37 times higher than those who had a meal frequency of more than three times per day [95\% Cl: 1.60 - 3.50]. Students who were living in food-insecure households had a 2.52 times higher chance of being stunted than those who were living in food secured households $[95 \% \mathrm{Cl}$ : 1.70 - 3.73]. (Table 3)

\section{Discussion}

The prevalence of stunting in this study was $27.5 \%$ and it is similar to a study conducted in Tigray (26.5\%) (15). This might be due to similarities in sociocultural conditions, feeding practice, economic growth, and level of awareness about the importance of proper nutrition during adolescent between the two regions of Ethiopia. However, this finding is higher than the one conducted in Addis Ababa (7.2\%) (21) and a report by the Ethiopian Health and Nutrition Research Institute (EHNRI) (23\%) (23). This difference might be related to variations in a level of awareness among Addis Ababa and Gondar town 
mothers. As a result, the importance of proper feeding practice and attention given for adolescent girls' nutrition by their families could be different in Addis Ababa than Gondar town. On top of this, the difference in prevalence between ours and the one by EHNRI might be related to the size of the study; while ours was confined to a single town, the EHNRI conducted a national survey.

Our estimate was lower than an estimates reported by a study conducted in adolescent girls of Amhara region (31.5\%) (17), Bangladesh (49\%) (24), India (50.3\%) (13), Indian early adolescent school girls (34.2 \%) (14), Nepal (47\%), and Myanmar (39\%) (11). These variations might be explained by differences in a study setting, economic status, socio-cultural conditions, data collection instruments, and study populations.

A high proportion of stunted students were observed in grade five than in grade eight. This finding was consistent with a study conducted in Jimma zone, which showed that stunting decreases with an increasing grade of students (25). This might be due to awareness about the importance of nutrition among students in higher grade (grade eight students) is better than students in a lower grade (grade five students). Participants who had a meal frequency of more than three times a day were less stunted than those reported a lower frequency, which is in line with a study conducted in Oromia region (21). It is true that adequate meal frequency accelerates a linear growth of adolescents by sufficiently supplying an important nutrients for their body size.

Adolescents who lived in food in-secured households had a higher chance of being stunted than those who lived in food secured households. This finding is in line with a study conducted in Amhara region and Dale Woreda $(16,19)$. This is due to the fact that food is very vital for the physical growth of adolescents in addition to its health benefit. Participants born from government employee and merchant mothers had a reduced chance of being stunted than those born from housewife mothers. This might be due to that housewife mothers may not get enough money to fulfil nutritional needs that are important for normal growth and development of their children's as compared to government employee mothers. In addition, housewife mothers are more likely to be uneducated, had low job access, and had low decision making power in the household that would affect their knowledge about nutrition and her ability to earn a better income to care for her kids (26).

As a limitation of this article, there is a potential for recall bias, especially in the food frequency questions. In addition, the cross-sectional nature of the study could not allow inferring the causal relationship between stunting and the identified predictors. Moreover, in few categories of variables included in the model like grade of students; it seems difficult to draw a conclusion using this few observations, however, as far as the assumptions for chi-square is fulfilled statistically it would not be affected. Therefore, the interpretation of this finding should be used in line with these inherent limitations. Apart from these inherent limitations, our study clearly showed that adolescent nutritional interventions have been lagging behind in Ethiopia (27) though adolescent is the best window to intervene such nutritional problems (28). We hoped the recent National Nutrition (NNP) Program and the National 
School-based Nutrition Program (NSBNP) would bring a significant change in reducing this burden of early adolescent nutrition (29).

\section{Conclusion}

The finding of this study demonstrated a significant public health problem of stunting in the early adolescent girls in school. Being in a lower grade, having mothers who were a housewife, having a daily meal frequency of fewer than three times, and those who were living in a household with food insecurity problem were at higher risk of being stunted. It is important to increase the food security status of the families especially females through improving their income. It is also important to increase nutrition awareness of the family and the adolescent girls to improve their proper nutritional intake and tackle the intergenerational effect of adolescent malnutrition.

\section{Abbreviations}

UN: United Nations

EHNRI: Ethiopian Health and Nutrition Research Institute

NNP: National Nutrition Program

NSBNP: National School based Nutrition Program

WHO: World Health Organizations

\section{Declarations}

\section{Ethics approval and consent to participate}

Ethical clearance of this study was granted by an Ethical Review Board of University of Gondar. Permission was also obtained from Gondar town Education office and selected schools. Written consent from the guardians and verbal assent from the study participants was secured prior to data collection. The information collected from this study was kept confidential. Those who were severely stunted were counseled about their nutritional condition.

\section{Availability of data and materials}

The data upon which the result based could be accessed by a reasonable request made to the corresponding author.

\section{Consent for publication}




\section{Competing interest}

Authors declare that they have no any conflict of interest

\section{Funding}

There was no specific funding for the research.

\section{Authors' contributions}

AT collected data, designed the study, performed analysis and interpretation of data. AFD and YY supervised the data collection, analysis, interpretation of data. YY and AFD drafted the manuscript. All authors read and approved the final Manuscript.

\section{Acknowledgements}

We would like to thank Gondar City Education Bureau, respective school administrative bodies, data collectors, and study participants for their unreserved contribution to the success of this work.

\section{References}

1. Merriam Webster Dictionary. https://www.merriam-webster.com/dictionary/adolescence (cited December 18, 2017). 2. Das Gupta M, Engelman R, Levy J, Gretchen L, Merrick T, Rosen JE: The Power of 1.8 Billion: Adolescents, Youth, and the Transformation of the Future, State of World Population, 2014. 3. Prentice AM, Jarjou LM, Moore SE, Fulford AJ, Ward K, Goldberg GR, et al. Critical windows for nutritional interventions against stunting reply. Am J Clin Nutr. 2013;98(3):856-7. 4. WHO. Global nutrition targets 2025: stunting policy brief. 2014. 5. Black RE, Victora CG, Walker SP et al.Maternal and child undernutrition and overweight in low-income and middle-Income countries.Lancet. 2013; 6: 15-39 6. Prentice AM, Ward KA, Goldberg GR et al. Critical windows for nutritional interventions against stunting.Am J Clin Nutr. 2013; 97: 911-918 7. McGuire S, World Health Organization. Comprehensive implementation plan on maternal, infant, and young child nutrition. Geneva, Switzerland, 2014. Adv Nut Int Rev J. 2015;6(1):134-5. 8. Akseer N, Al-Gashm S, Mehta S, Mokdad A, Bhutta ZA. Global and regional trends in the nutritional status of young people: a critical and neglected age group. Annals of the New York Academy of Sciences. 2017 Apr 1;1393(1):3-20. 9. Rengma M, Bose K, Mondal N. Socio-economic and demographic correlates of stunting among adolescents of Assam, North-east India. Anthropol Rev. 2016;79(4):409-25. 10. Kwon EJ, Kim YJ. What is fetal programming?: a lifetime health is under the control of in utero health. Obstet Gynecol Sci. 2017;60(6):506-519. 11. World Health Organization. 
Adolescent Nutrition: A Review of the Situation in Selected South-East Asian Countries. Reg Off SouthEast Asia, New Delhi. 2006;1-96. 12. Bishwajit G. Nutrition transition in South Asia: the emergence of non-communicable chronic diseases. F1000Research. 2015;4. 13. Mondal N, Sen J. Prevalence of stunting and thinness among rural adolescents of Darjeeling district, West Bengal , India. Ital J Public Health. 2010;7(1):54-61. 14. De D, Chatterjee K, Jana K. Prevalence of stunting and thinness among early adolescent school girls of Paschim Medinipur district, West Bengal. Int J Biol Med Res. 2011;2(3):781-3. 15. Mulugeta A, Hagos F, Stoecker B, Kruseman G, Linderhof V, Abraha Z, Yohannes M, Samuel GG. Nutritional status of adolescent girls from rural communities of Tigray, Northern Ethiopia. Ethiopian Journal of Health Development. 2009;23(1). 16. Wassie MM, Gete AA, Yesuf ME, Alene GD, Belay A, Moges T. Predictors of nutritional status of Ethiopian adolescent girls: a community based cross sectional study. BMC Nutrition. 2015 Dec;1(1):20. 17. Zelellw DA, Gebreigziabher BG, Alene KA, Negatie BA, Kasahune TA. Prevalence and associated factors of stunting among schoolchildren. Debre Markos Town and Gozamen Woreda, East Gojjam Zone, Amhara Regional State, Ethiopia. 2013:2. 18. Mekonnen $\mathrm{H}$, Tadesse T, Kisi T. Malnutrition and its correlates among rural primary school children of Fogera district, northwest Ethiopia. Journal of Nutritional Disorders and Therapy S. 2013;12:2161-0509. 19. Wolde M, Berhan Y, Chala A. Determinants of underweight, stunting and wasting among schoolchildren. BMC Public Health. 2015;15(1):1-9. 20. Prendergast AJ, Rukobo S, Chasekwa B, Mutasa K, Ntozini R, Mbuya MNN, et al. Stunting is characterized by chronic inflammation in zimbabwean infants. PLoS One. 2014;9(2). 21. Mohammed AY, Tefera TB. Nutritional Status and Associated Risk Factors Among Adolescent Girls in Agarfa High School, Bale Zone, Oromia Region, South East Ethiopia.. Int J Nutr Food Sci [Internet]. 2015;4(4):445. 22. Coates J, Swindale A, Bilinsky P. Household Food Insecurity Access Scale (HFIAS) for measurement of food access: indicator guide. Washington, DC: Food and Nutrition Technical Assistance Project, Academy for Educational Development. 2007 Aug;34. 23. Health E. Nutrition Basline Surevy Report for The National Nutrition Program of Ethiopia. Nutr Res. 2009 24. Rah JH, Christian P, Shamim AA, Arju UT, Labrique AB, Rashid M. Predictors of stunting and thinness in post-menarcheal adolescent girls in rural Bangladesh. Public Health Nutr. 2009;12(12):2400-9. 25. Assefa H, Belachew T, Negash L. Socio-demographic factors associated with underweight and stunting among adolescents in Ethiopia. Pan Afr Med J. 2015;20:252. 26. World Health Organization. Global nutrtion report from promise to impact ending malnutrition by 2030. 2016. 27. Delisle H, World Health Organization. Nutrition in adolescence: issues and challenges for the health sector: issues in adolescent health and development: 2005 28. Bhutta ZA, Das JK, Rizvi A, Gaffey MF, Walker N, Horton S, et al. Evidence-based interventions for improvement of maternal and child nutrition: what can be done and at what cost? Lancet. 2013;382 (9890):452-77 29. Federal Democratic Republic of Ethiopia. National Nutrition Programme June 2013June 2015. Addis Ababa: Government of Federal Democratic Republic of Ethiopia; 2013.

\section{Tables}

Due to technical limitations, tables are only available as downloads in the supplemental files section.

\section{Supplementary Files}


This is a list of supplementary files associated with this preprint. Click to download.

- Tables.pdf 